\title{
Trust and perceptions of compliance, fairness and good faith in primary labour relationships
}

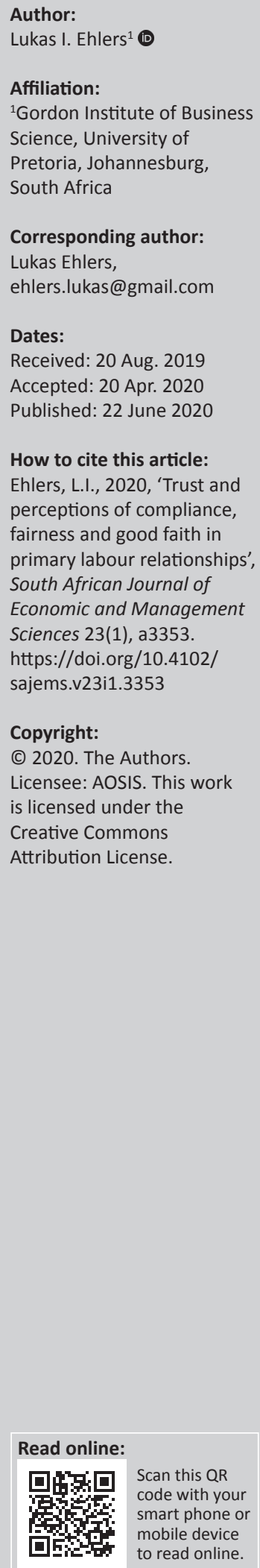

Background: Primary labour relationships (PLRs) occur within supervisory relationships. Previous studies confirmed that compliance, fairness, good faith and trust were interrelated facilitators of positive perceptions of primary labour relationship quality. Many researchers regard trust as a primary requirement for effective implementation of formal and psychological employment contracts.

Aim: This study investigated the nature and direction of relationships between subordinate employee perceptions of the levels of compliance, fairness and good faith in PLRs and levels of trust in PLRs.

Setting: Two interviewers adopted snowball sampling approaches to conduct structured interviews with 68 subordinate employees residing in Gauteng, South Africa.

Methods: The researcher adopted a mixed-method research methodology that included a thorough literature review, development of a structured interview, interviewing 68 voluntary participants and statistical analysis of data.

Results: Confident conclusions were drawn and discussed, and related limitations were explained. Specific recommendations for further research into the relationships and dynamics of trust-related phenomena in PLRs were made.

Conclusion: It was confidently concluded that literature and empirical findings, jointly and separately, provided ample evidence of positive relationships between subordinate employee perceptions of the levels of trust and their perceptions of the levels of compliance, fairness and good faith in PLRs. Accordingly, it can be confidently expected that lower levels of trust will be related to lower levels of perceived compliance, fairness and good faith in PLRs, and higher levels of trust will be related to higher levels of perceived compliance, fairness and good faith in PLRs. Causality was not investigated in this study.

Keywords: Primary; labour; relationship; supervision; compliance; fairness; good faith.

\section{Introduction}

\section{Background}

Trust can simply be defined as the willingness of a relationship stakeholder (trustor) to rely on another relationship stakeholder (trustee) to behave in an agreed or expected manner. Perceptions of trustworthiness can influence the trust relationship between trustors and trustees. A trustor will typically not expect exploitation by a trustworthy trustee, but will expect exploitation by an untrustworthy trustee (Krot \& Lewicka 2012). Trust is a fundamental requirement for effective human interaction, and has been described as the basic essence of social relations by Firmansyah et al. (2019). These definitions and assumptions are generally applicable in most types of social relationships, including labour relationships (Flanagan \& Runde 2009; Grogan 2017; Virues, Velez \& Sanchez 2019).

Labour relationship trust is a complex and dynamic social phenomenon that entails far more than mere compliance with laws and formalised work regulations (Searle \& Skinner 2011). Perceptions of the levels of labour relationship trust are normally subjective and are thus related to a plethora of employer and employee expectations (Williams 2007). These expectations are unique and typically informed by the trustor or trustee's unique experience of societal variables that affect them (Bendix 2015; Randy 2010). Numerous researchers have recommended further research into various aspects of trust in organisational and labour relationships (Cropanzano, Bowen \& Gilliland 2007; Fawcett, Fawcett \& Jin 2017; Krot \& Lewicka 2012). 
A recent study confirmed that subordinate employee perceptions of the levels of trust, compliance, fairness and good faith in supervisory relationships are interrelated. It was concluded that these perceptions are strongly related to subordinate employee perceptions of the levels of relationship quality in PLRs (Ehlers 2017). Unfortunately, the aforementioned study did not investigate the significance of differences between perceived levels of compliance, fairness and good faith in PLRs with lower and higher levels of trust.

No results of studies that specifically deal with relationships between subordinate perceptions of the levels of compliance, fairness and good faith and perceived trust levels in PLRs, or supervisory relationships, have been published recently. There is thus a knowledge gap in this regard.

\section{Research objectives}

This article aims to investigate the relationship between perceived levels of trust and perceptions of compliance, fairness and good faith in PLRs. The researcher subsequently investigated the validity of the following research propositions, and related hypotheses:

Proposition 1: There is a positive relationship between subordinate perceptions of the levels of compliance and trust in PLRs:

$\mathbf{H}_{0}$ : There are no positive relationships or significant differences as hypothesised.

$\mathbf{H}_{1}$ : There are positive relationships between subordinate perceptions of compliance and trust levels in PLRs.

$\mathbf{H}_{2}$ : There are significant differences between subordinate perceptions of compliance levels in PLRs with lower trust levels, and PLRs with higher trust levels.

Proposition 2: There is a positive relationship between subordinate perceptions of the levels of fairness and trust in PLRs:

$\mathbf{H}_{0}$ : There are no positive relationships or significant differences as hypothesised.

$\mathbf{H}_{3}$ : There are positive relationships between subordinate perceptions of fairness and trust levels in PLRs.

$\mathbf{H}_{4}$ : There are significant differences between subordinate perceptions of fairness levels in PLRs with lower trust levels, and PLRs with higher trust levels.

Proposition 3: There is a positive relationship between subordinate perceptions of the levels of good faith and trust in PLRs:

$\mathbf{H}_{0}$ : There are no positive relationships or significant differences as hypothesised.

$\mathbf{H}_{5}$ : There are positive relationships between subordinate perceptions of good faith and trust levels in PLRs.

$\mathbf{H}_{6}$ : There are significant differences between subordinate perceptions of good faith levels in PLRs with lower trust levels, and PLRs with higher trust levels.

\section{Definitions}

The following definitions were accepted for purposes of this article:

- Labour relationship trust can be defined as the willingness of a labour relationship stakeholder to rely on another relationship stakeholder to behave in an agreed upon or expected manner (Searle \& Skinner 2011).

- Compliance refers to compliance with explicitly defined laws, contracts, objectives, policies and procedures that regulate labour relationship conduct (Ehlers 2017; Grogan 2014).

- Fairness refers to even-handed exchanges in labour relationships. Such treatment includes awareness, objectivity, equity, consistency and reciprocity (Bendix 2015; Ehlers 2017; Venter \& Levy 2014).

- Good faith refers to displays of interest, sincerity, respect, consideration and constructivity aimed at the creation of maximum labour relationship benefits for all (Ehlers 2017; Heap 2009; Riley 2009; Shimanskaya 2010).

- Positive relationship means that an upward change in one variable is related to an upward change in another variable, irrespective of the causes of such changes. Likewise, a downward change in one variable will be related to a downward change in another variable (Cozby \& Bates 2015; Cresswell 2014).

- Perception refers to the process that individuals or groups of people use to organise and interpret their unique sensory impressions to give meaning to their social and physical environments (Robbins \& Judge 2017).

- Subordinate refers to an individual who performs work under instruction of another individual who is believed to be his or her immediate superior in some or other labour relationship (Lian et al. 2014).

\section{Overview}

The remainder of this article contains a literature review, a discussion of the mixed-method research methodology that was adopted in this study, a discussion of findings and an overview of limitations and recommendations of the study. Specific findings are described in the concluding section of the article.

\section{Literature review}

\section{Trust in labour relationships}

There are no laws that specifically require high levels of trust in labour relationships, even though trust is regarded as the foundation of labour relationships (Williams 2007). Labour relationship trust refers to the willingness of a vulnerable labour relationship stakeholder (trustor - very often an employee) to rely on a more powerful relationship stakeholder (trustee - very often an employer or employer representative) to behave in an agreed upon or expected manner (Cropanzano et al. 2007; Ehlers 2017). An employee will not typically anticipate exploitation by an employer when labour relationship trust levels are perceived to be 
high, and vice versa (Flanagan \& Runde 2009; Krot \& Lewicka 2012; Linde, Schalk \& Linde 2008; Searle \& Skinner 2011).

Numerous environmental variables that reside in the formal and psychological dimensions of labour relationships can influence trust levels in PLRs (Cropanzano et al. 2007). Trustworthiness perceptions of subordinates lay foundations for trust in PLRs. Mayer, Schoorman and Davis (2007) believe that such perceptions are strongly influenced by subordinate perceptions of the ability (skills, competencies means), benevolence (willingness to create benefits for subordinate) and integrity (predictability and reliability) of their supervisors. Ehlers (2017) found that interrelated subordinate perceptions of the levels of trust, compliance, fairness and good faith in supervisory levels are strongly related to their perceptions of relationship quality in PLRs.

Subordinate expectations, experiences and outcomes of previous trust exchanges will typically result in revised positive or negative perceptions of supervisor trustworthiness. These revised perceptions will then influence a subordinate's willingness to trust a supervisor in future trust exchanges. Subordinates of trustworthy supervisors are less likely to anticipate exploitation and could therefore be more willing to increase their trust in their supervisors. Accordingly, subordinates of untrustworthy supervisors are more likely to anticipate exploitation and could therefore be less willing to increase their trust in their supervisors and may even have distrust in their supervisors (Starnes, Truhon \& McCarthy 2016).

Coyle-Shapiro and Shore (2008) found that employees who are involved in organisational relationships with higher trust levels are more likely to put greater effort into their work and cooperate with their colleagues. They will also be less prone to displaying deviant workplace behaviours. Joint development of procedures, transparency in decision-making processes, responsiveness and the equitable distribution of benefits and risks are typical characteristics of work relationships in which higher levels of trust reside (Stern \& Coleman 2015). These characteristics are also closely related to certain behaviour forms that contribute to positive subordinate perceptions of the levels of trust, compliance, fairness, good faith and relationship quality in PLRs (Ehlers 2017).

A climate of trust facilitates an open and constructive relationship interaction and can prevent minor differences from evolving into dysfunctional labour relationship conflicts. Higher trust levels can also promote humane interpersonal relations in workplaces, and facilitate the effective prevention of inhumane, opportunistic and exploitative relationship behaviours (Flanagan \& Runde 2009;
Williams 2007; Kleptsova et al. 2018). Employees who have low levels of trust in their organisations will typically put less effort into their work and will also interact less effectively with their colleagues. Such employees will also be more likely to display deviant or undesirable workplace behaviours (Coyle-Shapiro \& Shore 2008; Lian et al. 2014).

At least five behaviour forms can be regarded as typical characteristics of labour relationships in which higher trust levels are evident. The absence of one or more of these characteristics will typically be related to less positive perceptions of trust in such relationships (Ehlers 2017). The five key characteristics of trust in PLRs are summarised in Table 1.

\section{Compliance in labour relationships}

Employers and employees are legally obliged to comply with all employment-related provisions of the Constitution, common law and statutory employment laws. These sources of labour law, and related case law, promote and regulate legal compliance, fair employment practices, good faith, fair discrimination and the equitable distribution of benefits in employment relationships, among numerous other objectives. Unreciprocated and charitable benevolence is, however, not an obligation of employers or employees under South African labour law (Grogan 2014; Viviers \& Smit 2014).

Additional formal guidelines, or control mechanisms, are typically introduced in labour relationships to ensure the effective and harmonious achievement of relationship objectives, and to reduce the risk of misinterpretation and labour conflict. Such guidelines include labour relations vision and mission statements, objectives, strategies, policies and procedures (Greenwood 2006; Searle \& Skinner 2011; Viviers \& Smit 2014). The various laws, contracts, policies and procedures that apply in labour relations establish clearly defined boundaries for relationship expectations and trust in such relationships, and should therefore be complied with by all relationship partners (Nel et al. 2016; Searle \& Skinner 2011; Venter \& Levy 2014).

Lower levels of trust are typical of labour relationships where employees perceive the implementation or nature of rules and procedures of their employers as unjustified or invalid (Linde et al. 2008; Williams 2007). However, ongoing compliance with valid and justifiable work procedures can result in positive levels of trust, commitment, job performance and customer satisfaction, and subsequently reduce the risk of labour relationship tension, conflicts and grievances. Compliance is strongly related to employee perceptions of procedural justice in their organisations, their identification

TABLE 1: Criteria for trust in labour relationships.

\begin{tabular}{|c|c|}
\hline Trust & Trust will be evident when parties are \\
\hline $\begin{array}{l}\text { A relationship partner is willing to risk vulnerability by relying on a } \\
\text { relationship partner to behave in an expected manner. }\end{array}$ & $\begin{array}{l}\text { - Convinced (undoubted acceptance of relationship objectives and partner bona fides) } \\
\text { - Devoted (committed to relationship objectives and performance of relationship duties) } \\
\text { - Tolerant (accepting relationship partner shortcomings and unforeseen relationship duties) } \\
\text { - Supportive (encouraging or assisting relationship partners to perform their duties) } \\
\text { - Loyal (acting in the best interest of a relationship partner - not exploiting partner vulnerabilities) }\end{array}$ \\
\hline
\end{tabular}

Source: Ehlers, L.I., 2017, 'Conceptualising primary labour relationship quality', South African Journal of Economic and Management Sciences 20(1), 1-18. 
with an organisation and their perceived sense of self-worth and job satisfaction. There is a strong relationship between positive employee perceptions of procedural justice, or compliance, and positive perceptions of organisational trust levels (Cropanzano et al. 2007; Holtz \& Harold 2009; Patel, Budwhar \& Varma 2012; Seppälä 2012).

Positive employee perceptions of compliance are also significantly related to positive perceptions of primary labour relationship quality (Ehlers 2017). In contrast, non-compliance with any source of labour law is a characteristic cause of perceived breaches of formal employment contracting expectations that typically result in numerous forms of relationship tensions, conflicts, grievances or disputes (Grogan 2014; Searle \& Skinner 2011; Venter \& Levy 2014). Positive perceptions of compliance in labour relationships result from active and justified compliance with numerous labour laws, contracts, policies and procedures. Negative compliance perceptions may result from non-compliance with such formal directives (Ehlers 2017).

Compliance can be assumed to be demonstrated in a labour relationship exchange when at least five interrelated compliance criteria are met. Failure to satisfy any one or more of these criteria during relationship exchanges will strongly suggest that the behaviour was non-compliant, Non-compliance will typically have a negative effect on compliance perceptions in PLRs (Ehlers 2017). The five criteria for assessing compliance in PLRs are summarised in Table 2.

\section{Fairness in labour relationships}

Fairness is perceived through the eyes of the beholders. Most assessments of fairness are therefore subjective and context dependent. Employers and employees can subsequently have different expectations or perceptions of fairness in work relationships. These differences often result in tension or relationship conflict (Robbins \& Judge 2017). Fairness can simply be defined as even-handed treatment in social relationships. Vulnerable societal members will be at risk of exploitation by more powerful societal members if fairness is not valued in a society (Viviers \& Smit 2014). Fair employment discrimination practices, fair labour practices, fair disciplinary or dismissal practices, fair employee representation practices and fair dispute resolution practices are subsequently explicitly and implicitly prescribed in numerous South African labour laws and related codes of good conduct (Grogan 2014; Venter \& Levy 2014).

Patel et al. (2012) highlight the need for fairness, equity and reciprocity in labour relationships. Such behaviours may reduce the likelihood of undesirable workplace behaviours, such as tension, grievances, absenteeism and social loafing. Other researchers agree that employees who believe that they are fairly treated in their employment relationships will be more likely to exceed their minimum job requirements or perform additional job duties. Such employees will also typically refrain from misconduct and other forms of undesirable work behaviour (Kickul, Gundry \& Posig 2005). Employees can also be confidently expected to be less sensitive to issues of fairness and equity in employment relationships with higher levels of trust (DiMatteo, Bird \& Colquitt 2011).

However, subordinate employee perceptions of unfair treatment can lead to lower levels of relationship trust and a variety of undesirable organisational outcomes. Some employees may resort to deliberately restricting their work output or sabotage work processes if they believe that they are unfairly treated or harassed in their work relationships (Commission for Conciliation Mediation And Arbitration [CCMA] 2011). Many employees are more likely to retaliate or litigate when they perceive a termination of their employment as procedurally and substantively unfair. Such retaliation typically results from the broken trust relationship (DiMatteo et al. 2011; Kickul et al. 2005; Southey 2010).

Fairness can be assumed to be demonstrated in PLRs when at least five interrelated behaviour criteria are met. Failure to satisfy any one or more of these criteria during relationship exchanges will strongly suggest that an exchange was unfair and will typically result in negative perceptions of fairness in PLRs (Ehlers 2017). The five criteria for assessing fairness in PLRs are summarised in Table 3.

TABLE 2: Criteria for assessing compliance in labour relationships.

\begin{tabular}{ll}
\hline Compliance & Compliance will be evident when parties are: \\
\hline $\begin{array}{l}\text { A relationship partner complies with all formal regulations that } \\
\text { apply to a labour relationship. }\end{array}$ & $\begin{array}{l}\text { - Constitutional (compliance with constitutional provisions) } \\
\text { - Cawful (compliance with applicable labour laws) }\end{array}$ \\
& - Directional (compliance with formal labour contracts or collective agreements) \\
& - Procedural (compliance with legitimate organisational strategies, policies and codes) \\
\hline
\end{tabular}

Source: Ehlers, L.I., 2017, 'Conceptualising primary labour relationship quality', South African Journal of Economic and Management Sciences 20(1), 1-18.

TABLE 3: Criteria for assessing fairness in labour relationships.

\begin{tabular}{ll}
\hline Fairness & Fairness will be evident when parties are: \\
\hline A relationship partner treats another labour relationship partner & - Informed (being aware of facts relating to an issue under discussion) \\
in an even-handed manner in labour relationship exchanges. & - Objective (acting in a neutral or impartial manner) \\
& - Equitable (treating actual equals as equals) \\
& - Recistent (acting in the same manner in similar circumstances at different times) \\
\hline
\end{tabular}

Source: Ehlers, L.I., 2017, 'Conceptualising primary labour relationship quality', South African Journal of Economic and Management Sciences 20(1), 1-18. 


\section{Good faith in labour relationships}

Goodwill towards relationship partners and genuine concern for their well-being and interests are generally regarded as typical characteristics of good faith (Dietz \& Hartog 2015; Hakanen 2017). Good faith can simply be defined as displaying honest and sincere intentions to create mutual benefits for all partners in labour relationships (Ehlers 2017; Heap 2009; Riley 2009; Shimanskaya 2010). Individual perceptions of good faith in the behaviour and decisions of superiors, as well as numerous other organisational behaviours, are believed to be strongly related to employee perceptions of trust levels in organisational relationships (Searle \& Skinner 2011).

Positive perceptions of good faith are related to higher levels of trust in organisational relationships, and organisational trust is positively related to several positive organisational behaviour outcomes. Conversely, negative perceptions of good faith, or displays of bad faith, are generally believed to be related to lower levels of trust in such relationships (Botha \& Moalusi 2010; Guest 2004). Positive perceptions of good faith have also been found to be strongly related to positive subordinate perceptions of relationship quality in PLRs (Ehlers 2017). Samadi et al. (2015) believe that frequent and convincing displays of good faith will promote gradual positive transformation and change in organisations and society and thereby decrease the need for the strict implementation of laws regulating unfair discrimination and affirmative action in workplaces.

The CCMA (2011) has identified numerous forms of workplace harassment that are typical examples of unfair workplace discrimination that relate to the absence of good faith in labour relationships. Some examples are mental bullying of subordinates, ridiculing subordinates in front of others, promoting less deserving employees, blocking employee progress, victimising employees, allowing special privileges to selected employees or intentionally blocking promotion of employees. Bad faith will thus become evident when one or more relationship partner acts in dishonest, insincere, rude, insulting, victimising, exploiting, abusing, harassing or intentionally disruptive manners in labour relationship exchanges (Bendix 2015; Grogan 2014).

As in the case of fairness, most assessments of good faith are also subjective and context dependent. Rights and obligations of employers and employees regarding good faith are not readily and clearly defined in labour laws, which makes it difficult to assess the legitimacy of differing expectations and perceptions of labour relations partners. Subsequently, diverging employer and employee expectations and perceptions of good faith often result in labour relationship tension and conflict, which in turn influence trust perceptions and levels in such relationships (Heap 2009; Robbins \& Judge 2017; Shimanskaya 2010).

Good faith can be assumed to be demonstrated in a labour relationship exchange when at least five interrelated behaviour criteria are met. Failure to satisfy any one or more of these criteria during relationship exchanges will strongly suggest that good faith was not displayed during the exchange and will often have a negative effect on good faith perceptions in PLRs (Ehlers 2017). The five criteria for assessing good faith in PLRs are summarised in Table 4.

\section{Research methodology}

Mixed methodologies allow researchers to make confident research assumptions despite unique research challenges, such as relatively small samples. In addition, mixed-method research studies can yield trustworthy findings that provide foundations for further development of theory, and a deeper understanding of the nature of phenomena under investigation, despite relatively small sample sizes (Cooper \& Schindler 2014; Cozby \& Bates 2015; Cresswell 2014; Fusch \& Ness 2015; Kumar 2011; Trotsuk 2016). The mixed research methodology that was devised for this study required a thorough literature review, identification of an appropriate sampling methodology, development of a valid and reliable research interview, definition of an appropriate sample, structured research interviews, capture and analysis of data and final integration of literature and data analysis findings. The following specific steps were followed in the study that preceded this article:

- A thorough literature review was undertaken on the nature of trust, compliance, fairness and good faith in PLRs, and a customised research interview was developed. Interview questions were selected after considering the objectives of the study, data required to test propositions and hypotheses, research interview guidelines, potential respondent characteristics and typical knowledge of concepts, language barriers and response options (Cozby \& Bates 2015; Cresswell 2014; Edwards \& Holland 2013; Kumar 2011).

- The draft structured interview contained three biographical questions relating to age, gender and years of employment, as well as 12 questions relating to perceptions of trust, compliance, fairness and good faith in PLRs. All interview questions were closed-ended and linked to specific quantified response options (Cozby \& Bates 2015; Kumar 2011; Trotsuk 2016). 
- Interview question validity was deemed to be higher than adequate, considering the very narrow alignment between questions and the respective hypotheses that were to be tested in this study (Edwards \& Holland 2013; Trotsuk 2016). Furthermore, the researcher developed a concise fact sheet that contained simplified definitions of trust, compliance, fairness and good faith. This fact sheet was explained to all interviewees before the start of interviews, and they could refer to a copy of the sheet at any time during the interview to ensure conceptual clarity.

- Ten voluntary respondents participated in mock research interviews and provided positive feedback on their structured interview experience. A Cronbach's alpha coefficient of 0.79 confirmed that the interview questions were more than adequately consistent (Cresswell 2014; Salkind 2014; Trotsuk 2016). The type of data that was obtained from interviews was also found to be appropriate for purposes of judging research propositions and related hypotheses.

- Two skilled interviewers then adopted snowball sampling approaches to conduct 68 structured interviews with voluntary research participants. All interviewees were employed in the larger Pretoria and Ekurhuleni areas of Gauteng, South Africa.

- The sample size of 68 far exceeded the generally recommended minimum sample size of 30 for qualitative research studies (Baker \& Edwards 2012; Dalphin et al. 2007; DePaulo 2000; Fusch \& Ness 2015; Guest, Bunce \& Johnson 2006; Mason 2010), as well as the generally recommended minimum sample size of 30 for effective application of inferential statistics in quantitative research studies (Cresswell 2014; Salkind 2014).

- Research data were captured, and descriptive and nonparametric inferential statistical analysis procedures were applied to judge the validity of the respective research propositions and related hypotheses. Salkind (2014) provide descriptions of the Spearman's Rho correlation test, Wilcoxon signed ranks test for two dependent samples and the Mann-Whitney $U$ test for testing the significance of differences in means between two independent samples.

\section{Discussion of findings}

The following section contains discussions of the validity of the respective propositions and hypotheses that were investigated in this study. Figure 1 reflects mean scores of interviewee perceptions of the levels of compliance, fairness and good faith in PLRs with lower, average and higher trust levels.

\section{Proposition 1: Relationship between compliance and trust in primary labour relationships}

It can confidently be assumed that there is a positive relationship between subordinate perceptions of the levels

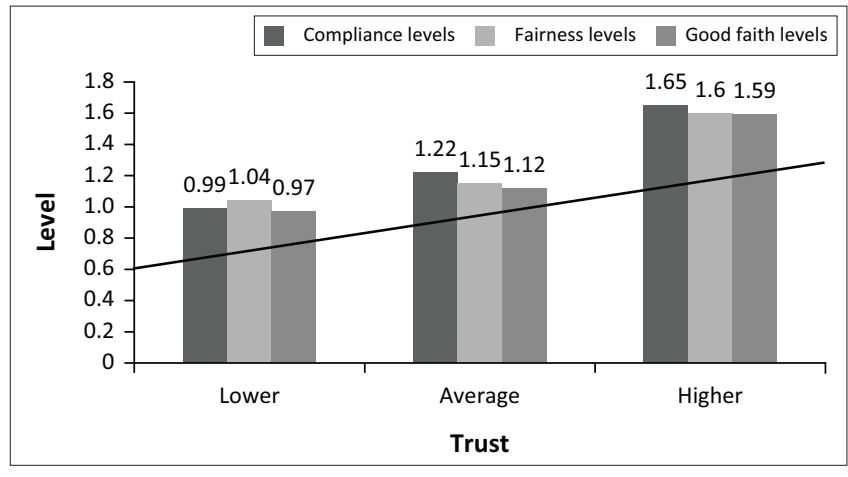

FIGURE 1: Levels of compliance, fairness and good faith at different trust levels in primary labour relationships.

of compliance and trust in PLRs. This assumption is strongly supported by reports in related literature (Cropanzano et al. 2007; Ehlers 2017; Grogan 2014; Holtz \& Harold 2009; Linde et al. 2008; Patel et al. 2012; Searle \& Skinner 2011; Viviers \& Smit 2014), and the following findings from this study:

- The perceived levels of compliance in PLRs with lower trust levels were average $(\bar{x}=0.99 ; s=0.72)$, and slightly higher than average in PLRs with average trust levels $(\bar{x}=1.22 ; s=0.64)$. However, compliance levels were perceived to be higher in PLRs with higher trust levels $(\bar{x}=1.65 ; \mathrm{s}=0.57)$. Figure 1 illustrates the positive relationship between perceived levels of compliance and trust in PLRs.

- $\mathrm{H}_{0}$ was rejected in favour of $\mathrm{H}_{1}$. The results of a Spearman's Rho correlation test confirmed that there is a statistically significant relationship between subordinate perceptions of compliance and trust levels in PLRs $(r=0.39, p<0.00)$.

- $\mathrm{H}_{0}$ was rejected in favour of $\mathrm{H}_{2}$. The results of a Wilcoxon signed ranks test confirmed that there is a statistically significant difference $(z=-6.94 ; p<0.00)$ between related subordinate perceptions of the levels of compliance in PLRs with lower and higher trust levels.

\section{Proposition 2: Relationship between fairness and trust in primary labour relationships}

It can confidently be assumed that there is a positive relationship between subordinate perceptions of the levels of fairness and trust in PLRs. This assumption is strongly supported by reports in related literature (Botha \& Moalusi 2010; Dietz \& Hartog 2015; DiMatteo et al. 2011; Ehlers 2017; Hakanen 2017; Patel et al. 2012; Robbins \& Judge 2017; Searle \& Skinner 2011; Stern \& Coleman 2015), and the following findings from this study:

- The perceived levels of fairness in PLRs with lower trust levels were average $(\bar{x}=1.04 ; s=0.68)$, and slightly higher than average in PLRs with average trust levels $(\bar{x}=1.15$; $s=0.58)$. However, fairness levels were perceived to be higher in PLRs with higher trust levels $(\bar{x}=1.60 ; s=0.55)$. Figure 1 illustrates the positive relationship between perceived levels of fairness and trust in PLRs. 
- $\mathrm{H}_{0}$ was rejected in favour of $\mathrm{H}_{3}$. The results of a Spearman's Rho correlation test confirmed that there is a statistically significant relationship between subordinate perceptions of fairness and trust levels in PLRs $(r=0.35, P<0.00)$.

- $\mathrm{H}_{0}$ was rejected in favour of $\mathrm{H}_{4}$. The results of a Wilcoxon signed ranks test confirmed that there is a statistically significant difference $(z=-6.78 ; P<0.00)$ between related subordinate perceptions of the levels of fairness in PLRs with lower and higher trust levels.

\section{Proposition 3: Relationship between good faith and trust in primary labour relationships}

It can confidently be assumed that there is a positive relationship between subordinate perceptions of the levels of good faith and trust in PLRs. This assumption is strongly supported by reports in related literature (Botha \& Moalusi 2010; Dietz \& Hartog 2015; Ehlers 2017; Samadi et al. 2015; Searle \& Skinner 2011; Stern \& Coleman 2015), and the following findings from this study:

- The perceived levels of good faith in PLRs with lower trust levels were average $(\bar{x}=0.97 ; s=0.83)$, and slightly higher than average in PLRs with average trust levels $(\bar{x}=1.12$; $s=0.64)$. However, good faith levels were perceived to be higher in PLRs with higher trust levels $(\bar{x}=1.59$; $s=0.58)$. Figure 1 illustrates the positive relationship between perceived levels of good faith and trust in PLRs.

- $\mathrm{H}_{0}$ was rejected in favour of $\mathrm{H}_{5}$. The results of a Spearman's Rho correlation test confirmed that there is a statistically significant relationship between subordinate perceptions of good faith and trust levels in PLRs $(r=0.33, P<0.00)$.

- $\mathrm{H}_{0}$ was rejected in favour of $\mathrm{H}_{6}$. The results of a Wilcoxon signed ranks test confirmed that there is a statistically significant difference $(z=-6.89 ; P<0.00)$ between related subordinate perceptions of good faith levels in PLRs with lower and higher trust levels.

\section{Below average levels of compliance, fairness and good faith}

It was noted that the perceived levels of compliance, fairness and good faith in PLRs with lower levels of trust were all very close to the average score of one $(0.97,0.99,1.04)$. These average levels gradually increased in PLRs with average $(1.22,1.15,1.12)$ and higher than average $(1.65,1.6,1.59)$ trust levels (see Figure 1). This trend suggests that levels of compliance, fairness and good faith could expectedly be perceived as below, or far below, average when trust levels are very low in PLRs. McKnight and Chervany (2014) believe that trust and distrust are not opposite ends of a continuum but two phenomena that exist alongside each other in social relationships. Increases in relationship trust are often related to, or even caused by, decreases in distrust, and vice versa. Distrust levels can therefore also be confidently expected to be higher when the levels of trust in PLRs are below average. Low levels of compliance, fairness and good faith, as well as non-compliance, unfairness and bad faith in organisational relationships are known to be related to higher levels of distrust and numerous related undesirable organisational relationship behaviours and outcomes (Flanagan \& Runde 2009; Kleptsova et al. 2018).

Damage to trust relationships, or increased distrust will typically arise when employers or employees fail to demonstrate legally or socially expected levels of compliance, fairness or good faith in PLRs. Such failures can also be perceived as breaches of written employment contracts or the regulations, policies and procedures that apply to PLRs in terms of such contracts. Perceived breaches of formal employment contracts can typically result in employee grievances, disciplinary action and labour disputes. Irreparable breaches of trust or intolerable levels of distrust in PLRs typically result in the termination of an employment contract by employers or employees (Bendix 2014; Grogan 2014). Breaches of subjective unwritten psychological contracts occur when subordinate employees perceive unfairness or bad faith in PLRs. Such perceptions may give rise to decreased levels of trust, and increased levels of distrust in PLRs. Perceived breaches of psychological contracts can also result in undesirable labour relationship tension, unresolved conflict, deviant workplace behaviours, stress, rumouring and numerous other undesirable relationship behaviours (Botha \& Molausi 2010; DiMatteo et al. 2011; Guest 2004).

The above-mentioned views in literature and findings from this study very strongly suggest that below, or far below, average levels of compliance, fairness and good faith could be typical of PLRs in which very low levels of trust or higher levels of distrust reside.

\section{Consistency of perceptions of different sample groups}

The sample size of 68 was adequate for mixed-method research studies but too small to make generalisable findings resulting from statistical analysis of data. Nonetheless, an investigation of the statistical significance of differences between the means of perceptions of different sample groups was undertaken to obtain some indication of differences between such perceptions. A non-parametric Mann-Whitney $U$ test was applied to determine if there were statistically significant differences between the mean scores of two independent sample groups, and yielded the following results (Salkind 2014):

- There are no statistically significant differences between male $(n=35)$ and female $(n=33)$ interviewee perceptions of levels of compliance, fairness or good faith in PLRs with different trust levels.

- There are no statistically significant differences between younger ( $0-35$ years, $n=34$ ) and older (36 years and older, $n=34$ ) interviewee perceptions of the levels of compliance, fairness or good faith in PLRs with different trust levels.

- There are no statistically significant differences between less experienced ( $0-10$ years, $n=39)$ and more experienced (11 years or more, $n=29$ ) interviewee perceptions of levels of compliance, fairness or good faith in PLRs with different trust levels. 


\section{Limitations and recommendations}

The relatively small sample and snowball sampling approach precluded this study from classification as a true quantitative research study, and findings from this study were subsequently interpreted from a mixed-method research perspective. Nonetheless, findings from a literature review and statistical analysis of research data confirmed that the research propositions and hypotheses under investigation were mostly true (Cozby \& Bates 2015; Cresswell 2014; Edwards \& Holland 2013; Trotsuk 2016).

There were no statistically significant differences between different sample group perceptions of the levels of good faith compliance, fairness and good faith at different trust levels in PLRs. Similar studies of related perceptions of employees in South African provinces other than Gauteng could facilitate further investigation of differences in perceptions and reassessment of the validity of the propositions and hypotheses of this study (Cresswell 2014; Salkind 2014).

The perceived levels of compliance, fairness and good faith in PLRs with lower and average trust levels were all relatively close to average (1) and noticeably higher in PLRs with higher levels of trust. Accordingly, it can be expected that very low levels of trust, or higher levels of distrust, in PLRs may be related to perceptions of below average levels of compliance, fairness and good faith in PLRs. The views of McKnight and Chervany (2014) may serve as foundations for further investigation into the relationships between distrust and trust levels in PLRs.

This study confirmed that there are positive relationships between perceived levels of compliance, fairness and good faith and trust levels in PLRs, but no findings on causality or the sequential development of compliance, fairness and good faith were made. Further research into causality and the sequence in which compliance, trust and fairness develop in PLRs could fill this knowledge gap. It could be worthwhile to conduct a thorough investigation into potential associations between underlying patterns in the situational leadership theory of Hersey and Blanchard, Maslow's hierarchy of needs and theories on labour relationship trust and quality perceptions PLRs (Ehlers 2017; Robbins \& Judge 2017).

\section{Concluding remarks}

This article reported on a study that was undertaken to investigate the relationship between perceived levels of trust and perceptions of compliance, fairness and good faith in PLRs. Findings from a literature review and statistical analysis of data were reviewed and integrated to arrive at the following conclusions:

- Positive subordinate employee perceptions of the levels of compliance, fairness and good faith are typically related to higher levels of trust in PLRs, and negative employee perceptions of the levels of compliance, fairness and good faith are typically related to lower levels of trust in PLRs. These assumptions were strongly supported in literature and empirical findings in this study.

- Increased displays of compliance, fairness or good faith by superiors in PLRs can be confidently expected to result in more positive subordinate perceptions of the levels of trust in PLRs. In contrast, inadequate or reduced displays of compliance, fairness or good faith by superiors in PLRs can confidently be expected to result in less positive subordinate perceptions of the levels of trust in PLRs.

- Literature and empirical findings from this study strongly suggest that it can confidently be expected that higher levels of distrust and very low levels of trust in PLRs will typically be related to far below average levels of compliance, fairness and good faith in PLRs. Correspondingly, it can confidently be expected that perceived levels of distrust in PLRs will increase in relation to increases in perceived levels of noncompliance, unfairness and bad faith in PLRs.

It can thus be confidently assumed that there are positive relationships between subordinate perceptions of the levels of trust and their perceptions of the levels of compliance, fairness and good faith in PLRs. Furthermore, there are significant differences between subordinate employee perceptions of the levels of compliance, fairness and good faith in PLRs with lower levels of trust and PLRs with higher levels of trust. Findings strongly suggest that levels of distrust in PLRs can confidently be expected to increase when subordinates perceive below average levels of compliance, fairness and good faith in such relationships.

Higher levels of trust in PLRs are related to numerous desirable labour relationship behaviours, outcomes and benefits for all stakeholders in such relationships. All stakeholders in all forms of PLRs should subsequently be continuously encouraged to actively establish, protect and promote compliance, fairness, good faith and, accordingly, higher levels of trust in such relationships.

\section{Acknowledgements}

The author would like to thank Martine van der Walt-Ehlers for editing and Athenkosi Mbuma for data collection.

\section{Competing interests}

The author has declared that no competing interests exist.

\section{Authors' contributions}

The author declares that he is the sole author of this research article.

\section{Ethical consideration}

Ethical clearance to conduct the study for purposes of this article was obtained from the Gordon Institute of Business Science of the University of Pretoria during August 2018. 


\section{Funding information}

The research received no specific grant from any funding agency in the public, commercial, or not-for-profit sectors.

\section{Data availability statement}

Data sharing is not applicable to this article.

\section{Disclaimer}

The views and opinions expressed in this article are those of the author and do not necessarily reflect the official policy or position of any affiliated agency or authors.

\section{References}

Baker, S.E. \& Edwards, R., 2012, How many qualitative interviews is enough? Expert voices and early career reflections on sampling and cases in qualitative research, pp. 1-43, National Centre for Research Methods, Southampton.

Bendix, S., 2015, Labour relations: A southern African perspective, 6th edn., Juta, Cape Town.

Botha, L. \& Moalusi, K.P., 2010, 'Values underlying perceptions of breach of the psychological contract', South African Journal of Industrial Psychology 36(1), 1-12. https://doi.org/10.4102/sajip.v36i1.817

Commission for Conciliation Mediation And Arbitration (CCMA), 2011, CCMA Infosheet: Harassment, viewed 12 February 2011, from http://www.ccma.org.za/ UploadedMedia/InfoSheets.

Cooper, D.R. \& Schindler, P.S., 2014, Business research methods, 12th edn., McGrawHill/Irwin, New York, NY.

Coyle-Shapiro, J.A. \& Shore, L.M., 2008, 'The employee-organization relationship: Where do we go from here?', Human Resource Management 17(2), 166-179. https://doi.org/10.1016/j.hrmr.2007.03.008

Cozby, P. \& Bates, S., 2015, Methods in behavioral research, 12th edn., McGraw-Hill Education, New York, NY.

Cresswell, J.W., 2014, Research design: Qualitative, quantitative and mixed-methods approaches, 4th edn., Sage, London.

Cropanzano, R., Bowen, D.E. \& Gilliland, S.W., 2007, 'The management of organizational justice', Academy of Management Perspectives 21(4), 34-49. https://doi.org/10.5465/amp.2007.27895338

Dalphin, J.R., Gary, P.S., Karp, D.A. \& Williamson, J.B., 2007, The research imagination: An introduction to qualitative and quantitative methods, Cambridge University Press, New York, NY.

DePaulo, P., 2000, 'Sample size for qualitative research', in Quirks marketing research media, viewed 11 April 2016, from http://www.quirks.com/articles/ a2000/20001202.aspx.

Dietz, G. \& Hartog, D.N., 2015, 'Measuring trust inside organisations', Personnel Review 35(5), 557-588. https://doi.org/10.1108/00483480610682299

DiMatteo, L.A., Bird, R.C. \& Colquitt, J.A., 2011, 'Justice, labour, and the psychological contract', in Selected works, University of Florida, viewed 15 October 2010, from http://works.bepress.com/larry_dimatteo/6.

Edwards, R. \& Holland, J., 2013, What is qualitative interviewing?, Bloomsbury, London.

Ehlers, L.I., 2017, 'Conceptualising primary labour relationship quality', South African Journal of Economic and Management Sciences 20(1), 1-18. https://doi. org/10.4102/sajems.v20i1.1573

Fawcett, S.E., Fawcett, A.M. \& Jin, Y.H., 2017, 'I know it when I see it: The nature of trust, trustworthiness signals, and strategic trust construction', The Internationa Journal of Logistics Management 28(4), 914-938. https://doi.org/10.1108/IJLM11-2016-0268

Firmansyah, M.R., Amelia, R., Jamil, R.A. \& Minza, M., 2019, 'Benevolence, competency, and integrity: Which one is more influential on trust in friendships?', Jurnal Psikologi 18(1), 91-105.

Flanagan, T. \& Runde, C., 2009, 'How teams can capitalize on conflict', Strategy \& Leadership 37(1), 20-22. https://doi.org/10.1108/10878570910926025

Fusch, P.I. \& Ness, L.R., 2015, 'Are we there yet? Data saturation in qualitative research', The Qualitative Report 20(9), 1408-1416.

Greenwood, M., 2006, 'Trust and the organisational-stakeholder relationship', Department of Management Working Paper Series 18(6), 1-12.

Grogan, J., 2014, Workplace law, 11th edn., Juta, Cape Town.

Guest, D.E., 2004, 'The psychology of the labour relationship: An analysis based on the psychological contract', Applied Psychology 53(4), 541-555. https://doi. org/10.1111/j.1464-0597.2004.00187.x

Guest, G., Bunce, A. \& Johnson, L., 2006, 'How many interviews are enough?: An experiment with data saturation and variability', Field methods 18(1), 59-82. https://doi.org/10.1177/1525822X05279903
Hakanen, M., 2017, 'The development and management of interpersonal trust in a business network in health, exercise, and wellbeing markets', Unpublished master's dissertation, Jyväskylä University, Jyväskylä.

Heap, L., 2009, 'Bad faith one day - Good faith the next?', in J. Riley (ed.), The debate: Good faith and the labour relationship No 2, pp. 8-9, Australian Institute of Employment Rights, Melbourne.

Holtz, B.C. \& Harold, C.M., 2009, 'Fair today, fair tomorrow? A longitudinal investigation of overall justice perceptions', Journal of Applied Psychology 94(5), 1185-1199. https://doi.org/10.1037/a0015900

Kickul, J., Gundry, L.K. \& Posig, M., 2005, 'Does trust matter? The relationship between equity sensitivity and perceived organizational justice', Journal of Business Ethics 56(3), 205-218. https://doi.org/10.1007/s10551-004-0992-0

Kleptsova, E.Y., Kleptsov, N.N., Mishutinskaya, E.A., Shubnitsyna, T.V. \& Tsvetkova, N.V., 2018, 'Psychological structure of humane interpersonal relations among the subjects of educational activity', Espacios 39(49), 1-15.

Krot, K. \& Lewicka, D., 2012, 'The importance of trust in manager-employee relationships', International Journal of Electronic Business Management 10(3), 224-233.

Kumar, R., 2011, Research methodology, 3rd edn., Sage, New Delhi.

Lian, H., Ferris, D.L., Morrison, R. \& Brown, D.J., 2014, 'Blame it on the supervisor or the subordinate? Reciprocal relations between abusive supervision and organizational deviance', Journal of Applied Psychology 99(4), 651-664. https:// doi.org/10.1037/a0035498

Linde, B.B., Schalk, M.J.D. \& Linde, H., 2008, 'Clarity and trust: The experience of workplace regulations by employees', South African Journal of Labour Relations 32(2), 86-103.

Mason, M., 2010, 'Sample size and saturation in PhD studies using qualitative interviews', Forum Qualitative Sozialforschung / Forum: Qualitative Socia Research 11(3), 1-19.

Mayer, R.C., Schoorman, F.D. \& Davis, J.H., 2007, 'An integrative model of organizational trust: Past, present, and future', Academy of Management Review 32(2), 344-354. https://doi.org/10.5465/amr.2007.24348410

McKnight, H. \& Chervany, N.L., 2014, 'Trust and distrust definitions: One bite at a time', viewed 22 February 2018, from https://www.researchgate.net/ publication/220793934.

Nel, P.S., Kirsten, M., Swanepoel, B.J. \& Poissat, P., 2016, South African labour relations, 8th edn., Van Schaik, Pretoria.

Patel, C., Budhwar, P.S. \& Varma, A., 2012, 'Overall justice, work group identification and work outcomes: Test of moderated mediation process', Journal of World Business 47(2), 213-222. https://doi.org/10.1016/j.jwb.2011.04.008

Randy, B., 2010, The science of interpersonal trust, viewed 21 February 2018, from http://scholarcommons.usf.edu/mhlp_facpub/574.

Riley, J. (ed.), 2009, 'Good faith in labour relationships', The debate: Good faith and the employment relationship. No 2: 2009, pp. 7-8, Australian Institute of Employment Rights, Melbourne.

Robbins, S. \& Judge, T., 2017, Organizational behaviour, 17th edn., Pearson, Boston, MA.

Salkind, N.J., 2014, Statistics for people who think they hate statistics, 5th edn., Sage, Los Angeles, CA.

Samadi, B., Wei, C.C., Seyfee, S. \& Yusoff, W.F.W., 2015, 'Conceptual model of organizational trust and knowledge sharing behavior among multigenerational employees', Asian Social Science 11(9), 32-42. https://doi.org/10.5539/ass. v11n9p32

Searle, R.H. \& Skinner, D., 2011, Trust and human resource management, Edward Elgar, Cheltenham.

Seppälä, T., 2012, 'Trust building and cooperation in supervisor-subordinate relationships and work units', Unpublished Master's dissertation, University of Helsinki, Helsinki.

Shimanskaya, I., 2010, 'The principle of good faith in European international trade', Unpublished Master's dissertation, University of Tampere, Tampere.

Southey, K., 2010, 'A typology of employee explanations of misbehaviour: An analysis of unfair dismissal cases', Journal of Industrial Relations 52(1), 81-102. https:// doi.org/10.1177/0022185609353991

Starnes, B.J., Truhon, S.A. \& McCarthy, V., 2016, 'Organisational trust: Employeeemployer relationships', viewed 21 February 2018, from https://asq.org/ hdl/2010/06/a-primer-on-organizational-trust.pdf.

Stern, M.J. \& Coleman, K.J., 2015, 'The multidimensionality of trust: Applications in collaborative natural resource management', Society \& Natural Resources 28(2), 117-132. https://doi.org/10.1080/08941920.2014.945062

Trotsuk, l., 2016, "'To trust or not to trust" is not the question; "How to study trust" is much more challenging task', Russian Sociological Review 15(4), 57-75. https:// doi.org/10.17323/1728-192X-2016-4-57-75

Venter, R. \& Levy, A., 2014, Labour relations in South Africa, 5th edn., Oxford University Press, Cape Town.

Viviers, D. \& Smit, D.M., 2014, 'A labour law perspective on the protection of persons in a vulnerable employment relationship in South Africa', International Journal of Business and Social Research 4(5), 59-71.

Virues, C., Velez, M. \& Sanchez, J.M., 2019, 'Entrepreneurs as trust's builders: An integrated model', Open Journal of Business and Management 7(3), 1298-1337. https://doi.org/10.4236/ojbm.2019.73091

Williams, M., 2007, 'Building genuine trust through interpersonal emotion management: A threat regulation model of trust and collaboration across
boundaries', The Academy of Management Review 32(2), 595-621. https://doi. org/10.5465/amr.2007.24351867 